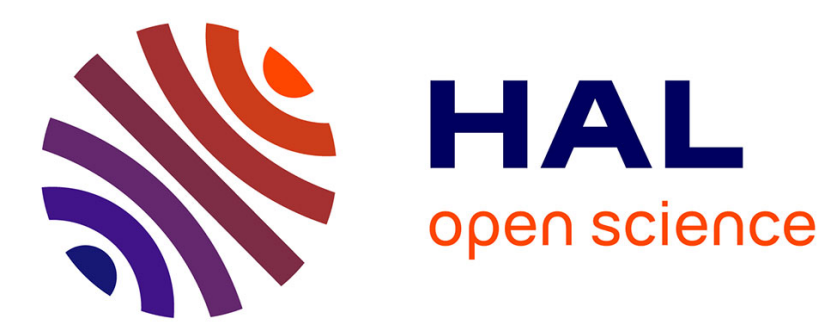

\title{
Reference dependence and incremental WTP
}

Karine Lamiraud, Robert Oxoby, Cam Donaldson

\section{To cite this version:}

Karine Lamiraud, Robert Oxoby, Cam Donaldson. Reference dependence and incremental WTP. 2016. hal-01342300

\section{HAL Id: hal-01342300 https://essec.hal.science/hal-01342300}

Preprint submitted on 5 Jul 2016

HAL is a multi-disciplinary open access archive for the deposit and dissemination of scientific research documents, whether they are published or not. The documents may come from teaching and research institutions in France or abroad, or from public or private research centers.
L'archive ouverte pluridisciplinaire HAL, est destinée au dépôt et à la diffusion de documents scientifiques de niveau recherche, publiés ou non, émanant des établissements d'enseignement et de recherche français ou étrangers, des laboratoires publics ou privés. 


\title{
E \\ ESSEC \\ BUSINESS SCHOOL
}

\section{REFERENCE DEPENDENCE AND INCREMENTAL WTP}

\author{
RESEARCH CENTER
}

KARINE LAMIRAUD

ESSEC WORKING PAPER 1609 


\section{Reference Dependence and Incremental WTP}

\section{Karine Lamiraud ${ }^{1}$, Robert Oxoby ${ }^{2}$ and Cam Donaldson ${ }^{3}$}

Keywords: WTP, contingent valuation, reference points, embedding effect, incremental approach, emergency care

JEL: D6, H4, I1

1. Corresponding author. Department of Economics, ESSEC Business School, Avenue Bernard Hirsch, B.P. 50105, 95021 Cergy, France.

Other affiliation: THEMA-University of Cergy Pontoise, 33, boulevard du Port, 95011 CergyPontoise Cedex, France.

Email: lamiraud@essec.edu

Phone: (33) 6294602 25, (33) 134433665

2. Department of Economics, University of Calgary, 2500 University Drive NW Calgary, AB Canada T2N 1N4

3. Yunus Centre for Social Business \& Health, Glasgow Caledonian University, Level 3 Buchanan House, 58 Port Dundas Road, Glasgow G4 0BA 


\begin{abstract}
Applications using the standard willingness to pay (WTP) approach (where a respondent is asked his/her WTP for each option) have brought to light inherent difficulties in terms of discriminating between various options. Although an incremental WTP approach (where a less preferred option is used as a point of reference to value more preferred options) has been devised to encourage more discrimination, a theoretical basis for this approach has not been elucidated, and results from initial testing of this approach have proved inconclusive. We offer a theoretical basis for this approach, based on the theory of reference dependent preferences. We test our model in a study assessing preferences for emergency care services in France. Our empirical findings are in line with our theoretical framework, showing the standard WTP approach fails to discriminate between alternative options for which there is a strict preference ranking. The incremental approach provides discriminating values and provides a better method for determining preferences in priority-setting and policy contexts.
\end{abstract}




\section{Introduction}

The use of direct willingness to pay (WTP) methods to value publicly-funded amenities remains a controversial issue. This is partly because it involves monetary valuation of the benefits of such amenities, but also because its use in such contexts involves examining hypothetical scenarios. Nevertheless, given the persistent use of cost-benefit analysis (CBA) methods and the necessity for decision makers to make choices between alternative options, it could be argued that the real question is whether the validity of explicit WTP valuation can be improved upon.

Controversy dates as far back as the National Oceanographic and Atmospheric Administration (NOAA) Panel's recommendations on the conduct of such studies (NOAA, 1993) and the related negative views first expressed by Diamond and Hausman (1994) and recently reinforced (Hausman, 2012). The key point is that when several competing options for public funds are being evaluated, the standard practice of eliciting a WTP value for each option fails to discriminate between all the options, whether using within- or between-respondent comparisons.

This lack of discrimination has been blamed on embedding, most commonly evidenced as a failure to discriminate between different sizes of a given good (Schkade and Payne, 1994). In health care, there are many examples of a more general form of embedding whereby respondents state a preference for one type of health care over another, but WTP values fail to discriminate these preferences in the same way (Olsen and Donaldson, 1998). Each of these examples of embedding could be attributed to various motives, one of which being the purchase of moral satisfaction, wherein respondents indicate their general sympathy with a broad type of amenity (say, health care) by stating the same WTP for specific forms of that amenity (Kahneman and Knetsch, 1992).

The above challenges to the standard use of WTP has led to an alternative incremental WTP approach where a less preferred option is used as a point of reference to value more preferred options (Shackley and Donaldson, 2002). However, this approach proved inconclusive, failing to reveal a consistent revelation of preferences and being unable to strongly discriminate preferences among the options under consideration. Here, we focus on developing theoretical basis for the incremental approach and empirically explore the approach's ability to discriminate 
between preferences over alternatives. In a previous study (Lamiraud et al 2016), we investigated the internal consistency of the incremental approach, focusing on the extent to which the incremental approach improves consistency with ordinal ranking. In our present study, we are focused on the ability of the incremental approach to allow for discernment of different policy options, thereby emphasizing the use of the incremental approach as tool for policy assessment.

The development of the approach, including potential practical improvements to the survey method, is outlined in the next section. Following this, we present a theoretical basis for the approach based on reference-dependent preferences. This builds on theories of referencedependency for addressing both the endowment effect and using reference points to generate more-structured preferences and recovering “explanatory power” (Giraud, 2010). In the work outlined, we are less concerned with overcoming the issue of status quo bias (to which referencedependent theory has been usefully applied (Sagi, 2006; Masatlioglu and Ok, 2005)) and more with examining how to achieve more discriminating answers.

After outlining our hypotheses, we present an empirical test of the incremental WTP theory based on a survey of the general public to assess their preferences for mutually exclusive options for publicly-funded emergency and out-of-hours health services in France. The results of the study are discussed in terms of their implications for the stated theory and for future research and policy.

\section{Background and proposed theory}

\subsection{The incremental approach}

In many non market settings (e.g., policy makers considering the implementation of one from a menu of alternatives) where choices must be made over the allocation of resources, simple tasks can be devised to identify population preferences. A traditional approach among economists has been to have consumers rank competing programmes and compare elicited WTP valuations (and the ranking implied by these WTP) against this ranking. Given the competition for public funding, each programme is typically evaluated by each respondent (Boardman et al., 1996; Luchini et al., 2003). As WTP valuations and rankings are aggregated at the population level, WTP values are all too often unable to discriminate preferences between various programmes. As 
seen in many studies, this is evidenced by WTP values that contradict stated rankings or equally value policy options while a clear preference emerges in the rankings. To address these problems, practitioners have argued that these results are the consequence of flawed study designs (Carson et al., 2000; Smith, 2003) and that WTP responses are often influenced by the respondent's reference point (Kahneman et al., 1991; Morrison, 2000). Although theories of reference dependency have been developed to address issues of endowment effects, imprecise preferences, and status quo biases (Sagi, 2005; Masatlioglu and Ok, 2005; Giraud, 2010), little has been done to operationalize WTP methods to specifically address issues related to embedding. Here, we propose an approach wherein we explicitly utilize reference dependency on a less preferred alternative when eliciting WTP responses. In this way, we operationalize reference dependency to yield discriminating WTP results over policy options.

Shackley and Donaldson's (2002) incremental WTP approach was developed to encourage more differentiated WTP responses. Although their approach did not discriminate between competing options as much as hoped, we have developed this approach further in two ways: first, by trying to ensure that respondents understood that their outstanding 'budget' was not diminished by the WTP values they provided for previous (i.e. less preferred) programmes, which was not explicitly stated by Shackey and Donalfdson (2002); and, second, by each successive programme being valued above that ranked immediately below it, thereby providing consistent incremental measures of valuation. On this latter issue, Shackley and Donaldson (2002) valued each other option against the baseline. One possible criticism of the change reported here is that consistency is (more) forced. Nevertheless, one could also argue that such a basic test of rationality is fundamental for any method to be validated. Moreover, the incremental approach has never been compared directly with the conventional approach of providing a total WTP for each competing programme.

\subsection{Theoretical framework}

The incremental approach is built on the theory of reference dependent preferences (Koszegi and Rabin, 2006; Munro and Sugden, 2003; Schoemaker, 1982). In line with this theory, we assume an individual's response to a WTP question is influenced by their reference point. In line with our 
study, we focus on the amenity under evaluation being health care. As we can see in Figure 1, the policy maker must choose an efficient level of the amenity $h$, where $h_{i} \in H$ is an exogenously determined level of health amenity (e.g., a health policy or service provider) available to an individual among the larger set of services $H$. Individuals also have preferences over $\boldsymbol{x}$, a vector of $n$ consumption goods. An individual's preferences are described by the utility function $u\left(x, h_{i} ; h_{0}\right)$, where $h_{i}$ is the (exogenously determined) level of the amenity under evaluation, $h_{0}$ is the agent's reference level of the amenity (perhaps their status quo level of medical treatment), and $h_{i}, h_{0} \in H$. We assume $u\left(x, h_{i} ; h_{0}\right)$ to be increasing, continuous, concave, and differentiable in $x$ and $h_{i}$. We also assume that

$$
\partial u(.) / \partial \boldsymbol{x} \rightarrow 0 \text { as } \boldsymbol{x} \rightarrow \mathbf{0 .}(a)
$$

In accordance with other theories and empirical research on reference dependency (e.g., Heath et al, 1999; Kahneman and Knetsch, 1992), equation (a) implies individuals are more sensitive to changes in consumption bundles closer to their reference point than those more distant from their reference point. Experimentally, Heath et al (1999) find support for this assumption in their use characterization of goals as reference points: individuals are more sensitive to marginal changes around a reference point when said reference point is closer to their status quo position. Morrison and Oxoby (2013) find a similar sensitivity to marginal changes in financial decision making environments when the reference point changes. In an empirical investigation using marathon runners, Allen et al (2014) find empirical support for equation (a).

As such, equation (a) assumes that the concavity of $u(\cdot)$ in $h_{i}$ is relative to the reference level $h_{0}$. Thus small changes in $h$ above or below the reference level yield larger changes in marginal utility, with changes declining for subsequent increases or decreases beyond the reference level. This is equivalent to, using Figure 1, the marginal rate of substitution being larger when one is making comparisons around the bundle $\left(x_{0}, h_{1}\right)$ based on a reference point of $h_{1}$ (indifference curve $u_{1}$ ) than when one is making similar comparisons using a reference point of $h_{0}$ (indifference curve $u_{0}^{\prime}$ ). Mathematically, this is equivalent to assuming that 


$$
\frac{\partial^{2} u\left(\mathbf{x}, h_{i} ; h_{0}\right)}{\partial h_{i} \partial h_{0}}>\left(\frac{\partial^{2} u\left(\mathbf{x}, h_{i} ; h_{0}\right)}{\partial \mathbf{x} \partial h_{0}}\right)\left(\frac{\partial u\left(\mathbf{x}, h_{i} ; h_{0}\right)}{\partial \mathbf{x}}\right)^{-1} \cdot(b)
$$

Note that if utility is separable in $\mathbf{x}$ and $h$, it is sufficient to assume that

$$
\frac{\partial^{2} u\left(\mathbf{x}, h_{i} ; h_{0}\right)}{\partial h_{i} \partial h_{0}}>0 .(\mathrm{c})
$$

Reference dependency (see Fig 1) implies that an individual places greater value on marginal changes closer to their reference point. Accordingly, if individuals are initially at $\left(x_{0}, h_{0}\right)$, with preferences given by $u_{0}$, an exogenous increase in $h$ to $h_{1}$ will shift their indifference curve to $u_{0}{ }^{\prime}$ (Note: since the new level of healthcare is given, the individual cannot trade from $\left(x_{0}, h_{1}\right)$ to a preferred bundle). However, when $h_{1}$ becomes the agent's new reference point, their indifference curve is now represented by $u_{1}$ and no longer $u_{0}{ }^{\prime}$. Given their new reference point, the individual now values marginal changes around $h_{1}$ (measured by the slope of $u_{1}$ at $h_{1}$ more than they did when valuing changes from their old reference point of $h_{0}$ (measured by the slope of $u_{0}{ }^{\prime}$ at $\left.h_{1}\right)$ ). The crossing of indifference curves at the point $\left(x_{0}, h_{1}\right)$ does not imply that the individual is indifferent about bundles along $u_{0}{ }^{\prime}$ and $u_{1}$. Each of these indifference curves is distinct and defined for a different reference level $h$.

This formulation of preferences has similarities to recent developments in characterizing reference dependency. While we take a standard modelling approach to reference dependency (incorporating a reference point directly into the utility function), axiomatic approaches to reference dependency have enabled other approaches to welfare measurements. Most recently, Ok et al (2015) develop an axiomatic approach to reference dependency in which the weak axiom of revealed preference is relaxed to account for the behavioural phenomena associated with reference dependency. The authors postulate "reference acyclicity,” an axiom providing a level of consistency to changes in the reference point and the corresponding effect on choice. A similar “no-cycling” approach is taken by Sagi (2006) to maintain transitivity within a decision environment with changing reference points. Similarly, Masatlioglu and Ok (2005) establish a 
rational choice framework for reference dependency in which reference dependency is characterized by the use of a nested series of preference relations.

Our approach is closer to that of Masatlioglu and Ok (2005) in that one could characterize different reference points as nested relations within our overall utility maximizing framework. Previously, Lamiraud et al. (2016) presented a highly stylized model of a reference dependency focusing on the minimum criteria necessary for consistency of preferences. In that model, we specifically explored on role of reference dependency in preference rankings and demonstrated the explicit use reference points to augment and enhance the consistency of simple rankings. In constrast, here we present a robust interpretation of reference dependency, highlighting the characteristics required in both a separable and non-separable environments. We demonstrate how the use of a reference point can lead to more discriminating WTP valuations among competing options. As such, this yields a tractable approach for policy makers applying our incremental approach, moving this method forward beyond mere preference consistency among policy alternatives to a practical implementation in policy setting.

In the current study, we do not postulate reference acyclicity. Rather our consideration is on the application of eliciting WTP valuations where individuals have different reference points in the dimension of $h$ but are measuring a policy option $h_{i}$ that is more preferred than the reference point. In our application, one should consider a policy maker asking for a ranking of alternatives, and then measurement across a subset of those rankings (e.g., most preferred against next-most preferred) where respondents are asked to consider the least preferred alternative as a reference point. This tried to capture the idea that, if only two policies are to candidates for implementation, the opportunity cost of one alternative is not the status quo, but rather the other alternative under consideration. By fixing the reference point (by the policy maker) we maintain transitivity of choice.

Towards this end, assume a policy maker is contemplating two potential changes that would raise the level of $h$ from $h_{0}$; one set raising the level to $h_{1}$, another to $h_{2}$. In Figure 1 we assume that, for our representative individual, $h_{1}>h_{2}$. However, one could also assume a set of preferences where the individual views $h_{2}>h_{1}$, given her particular health status or medical needs. We 
interpret $\operatorname{WTP}\left(h_{i}, h_{0}\right) \in[0, y]$ as the income the individual is willing to forgo for an increase in health amenity from $h_{0}$ to $h_{i}$, such that his utility remains unchanged from when only $h_{0}$ was available. To discern the optimal policy (measured in terms of potential Pareto improvements) the policy maker could ask $I_{1}$ individuals for $\operatorname{WTP}\left(h_{1}, h_{0}\right)$ and $I_{2}$ individuals for $\operatorname{WTP}\left(h_{2}, h_{0}\right)$. For simplicity and without loss of generality, we assume $I_{1}=I_{2}$. (Alternately, one could measure average valuations in equation d.) If WTP is considered a metric for individuals' preferences, a policy maker can use the reported WTP values to determine the optimal $h^{*}$ policy. This would be calculated via the index

$$
\beta\left(h_{2}, h_{1} ; h_{0}\right)=\sum_{i \in I_{2}} W T P\left(h_{2} ; h_{0}\right)-\sum_{i \in I_{1}} W T P\left(h_{1} ; h_{0}\right)(\mathrm{d})
$$

No attempt is made here to discern individuals' preferences between $h_{1}$ and $h_{2}$. Each is valued relative to the reference point, $h_{0}$. In a sense, the individual perceives the opportunity cost of each of $h_{1}$ and $h_{2}$ to be $h_{0}$ (i.e., both options have the same cost). Figure 2 shows the measure $\beta\left(h_{2}, h_{1} ; h_{0}\right)$ for an individual preferring $h_{2}$ to $h_{1}$. With $x$ as income (or the numeraire),

$$
\operatorname{WTP}\left(h_{1} ; h_{0}\right)=x_{0}-x_{1} \text { and } \operatorname{WTP}\left(h_{2} ; h_{0}\right)=x_{0}-x_{2} \text {. }
$$

$\beta\left(h_{2}, h_{1} ; h_{0}\right)$ is represented by the difference $x_{1}-x_{2}$, which is small and becomes smaller the larger the improvement in both $h_{1}$ and $h_{2}$ over $h_{0}$. Accordingly, one could infer that the individual is effectively indifferent about the two policy options, and this is essentially the embedding problem.

However, for a policy maker the two options $h_{1}$ and $h_{2}$ do not have the same opportunity cost. Namely, if policy makers can only implement one policy (e.g., due to budget constraints) the true opportunity cost of, say, $h_{1}$ is not of $h_{0}$ but rather $h_{2}$. Exploiting reference dependency to provide a more discerning measure of preference and strength of preference, Figure 3 illustrates the incremental approach wherein the individual is asked to rank the alternatives $h_{1}$ and $h_{2}$ and then asked her willingness to pay for $h_{2}$ given a reference point of $h_{l}$. Preferences are now described by $u_{1}$, and the increase to $h_{2}$ shifts the individual's indifference curve to $u_{1}{ }^{\prime}$. We can now define a new statistic to measure the willingness to pay between these two options:

$$
\beta^{\prime}\left(h_{2}, h_{1} ; h_{1}\right)=\sum_{i \in I_{2}} W T P\left(h_{2} ; h_{1}\right)-\sum_{i \in I_{1}} W T P\left(h_{1} ; h_{1}\right) \text {.(e) }
$$


The latter term of $\beta^{\prime}$ may be zero (valuation of a reference point from that reference point), but note that, given our initial assumption, $\beta^{\prime}>\beta$. Thus, vertical difference between the curves at the relevant point (here $h_{2}$ ) represented by $x_{1}^{\prime}-x_{2}^{\prime}$ is greater than the corresponding gap in Figure 2 and our $\beta$ ' index provides a more-discriminating result in terms of strength of preference between $h_{1}$ and $h_{2}$.

Given that there is a requirement to choose between the specific policy options and that a genuine difference exists between these options in the minds of respondents, then the harnessing of reference dependency in this way provides an improvement through highlighting the differences between the policy options. More specifically, we would hypothesise that:

- When asked to value several competing policy alternatives, respondents are likely to compare each of these against a status quo or 'do nothing' option, and, when these policy options are close substitutes, the respondent is essentially evaluating each policy variation against a common opportunity cost, and thus a non-discriminating set of valuations, or $\beta$ index, will arise; and, conversely,

- When defining a new reference point, which might be based on the respondent's least preferred form of the amenity, a more-discriminating $\beta$ index will be obtained.

These are the issues to be investigated in the forthcoming empirical study of emergency services in France. This empirical study serves as a good example because it takes place within the context of trying to evaluate several mutually exclusive options competing for limited resources within a cash-limited publicly-funded system.

\section{Data}

\subsection{Emergency and out-of-hours medical services in France}

There are six emergency and out-of-hours medical assistance providers in France. Table 1 shows fixed and mobile services. The latter come to the patient's location and include SAMU/SMUR, SOS Doctors, physicians on duty, ambulance/firemen. Fixed services include outpatient emergency centers and emergency hospital units where the patient travels to. All six services are financed by the national social health insurance system. In France granting access to emergency 
or out-of-hours medical care is generally preceded by a telephone call, whereby the operator first assesses the seriousness of the emergency, and then either dispatches a mobile service or requests the caller to go to an emergency unit. Despite this system's goal of maximizing scarce resources, the debate surrounding the optimization of emergency and out-of-hours care is still open. Data on public preferences for the different provision services could help inform future choices. We address this issue by presenting a study of WTP for the competing service providers, comparing the incremental WTP approach with conventional WTP elicitation. This study also contributes to the scarce literature evaluating emergency and out-of-hours medical services (Hackl and Pruckner, 2006; Van Uden et al., 2003).

\subsection{Survey}

Between July 17th and July 27th 2009 the polling Institute TNS Sofres carried out a telephone survey assessing preferences for these different emergency services from a representative sample of the French adult population living in urban areas with over 100,000 inhabitants ${ }^{1}$. Respondents were randomly assigned either a standard or incremental WTP questionnaire, creating two study samples to test our theory.

\subsection{Questionnaires}

Both questionnaires were divided into four sections.

The interviewer first provided introductory information, describing the characteristics of emergency and out-of-hours medical providers (as described above) to ensure all respondents had the same knowledge. The interviewer also told respondents to assume that the costs of the six providers were equal when answering the questionnaire. Respondents then ranked the providers in order of preference, from their most (ranked 1) to their least (ranked 6) preferred provider. In the third section of the questionnaire, they were asked to imagine that financing mechanisms for all six providers had been changed, and consequently the necessary resources would have to be paid for by private households through insurance premia. Only those subscribing to the

\footnotetext{
${ }^{1}$ This choice was driven by the fact that the number of emergency and out-of-hours providers is much lower in rural areas
} 
corresponding insurance contracts would be able to benefit from emergency care or out-of-hours services. Given this hypothetical situation, respondents were asked what their maximum WTP was in terms of monthly insurance premia. The fourth section collected information about sociodemographic variables, health status, and supplementary coverage. Respondents were also asked whether they had contacted any of the six emergency providers during the previous year.

The third section of the standard and incremental WTP questionnaires differed. In the former, respondents were asked about the maximum premium they would pay for each emergency and out-of-hours provider (Appendix 1), one question per each provider. The order of these questions was randomized to avoid sequence effects (Payne et al., 2000). Furthermore to avoid respondents 'totalling' their WTP amounts (and thereby paying less for later options because of perceived budget constraints), it was indicated to the respondents to imagine that they were given back all the money they indicated for the previous provider before valuing the subsequent provider. Instead, in the incremental questionnaire, after the ranking exercise in the second section, the lowest ranked provider was selected for the first WTP valuation. This became the reference point for each respondent, beyond which each successive programme was valued above that ranked immediately below it. Respondents were asked about the maximum premium that they would pay for the provider ranked sixth and then asked how much more they would pay for the fifth-ranked provider over and above that ranked sixth, for the fourth over and above that ranked fifth, and so on. Again, they were told to imagine they were given back the full amount they were willing to pay for the previously valued provider before valuing the subsequent one.

The following method was used to elicit WTP values in the standard approach: the interviewer first randomly cited one of 20 possible amounts ranging from " 5 ” to "more than 180 euros" per month (Appendix 1). These amounts coincided with the range of the most popular complementary health insurance products offered at the time of the study. If a respondent indicated that this was an amount he/she would definitely pay, the interviewer cited the next highest amount until the respondent said "no" or until the category "more than 180 euros" was reached. If the respondent answered "no" to the first cited amount, the interviewer cited the next lowest amount until the respondents said yes or until " 5 euros" was reached. The last (first) value to which the respondents said "yes", going up (down) the scale, was defined as the maximum 
WTP. If the respondent said "no" to " 5 euros", she/he was asked whether he would be willing to pay anything for the offered product: if he/she answered "no", this was treated as a zero value; if he/she answered “yes”, a WTP equal to 2.5 euros was assigned.

The same method was used to elicit incremental WTP values, except for the fact that we used a range of smaller amounts (5 - 100 euros).

An ex ante WTP approach (where neither the need for care nor the outcomes are known for certain) was chosen over an ex post WTP approach (where respondents' conditions, but not necessarily the outcome, are known for certain) because of the emergency care-based context. In case of extreme emergencies WTP may converge to infinity if respondents are made to imagine that they suffer from acute pain. To date, ex ante type approaches have used both insurance premiums and taxation contributions (Olsen et al, 2004). We chose the former as most French people pay (and understand) premiums for complementary health insurance coverage. Instead, a tax increase approach might have induced many protest answers.

In order for the valuation question to be meaningful, we followed Mitchell and Carson's guidelines (1989). First, the overall scenario can be seen as meaningful, in that respondents knew that these services were alternatives to each other. Second, the scenario can be regarded as policy relevant, in that there is a need to optimize across the options. Finally, it is theoretically accurate, in that the opportunity cost of more resources for one option would mean fewer for another (so it is important to know strength of preference of each individual for each option).

\subsection{Statistical and econometric methods}

The purpose of the empirical analysis was to test whether the incremental approach made it possible to differentiate between the various providers.

In the incremental questionnaires, the WTP for each provider was computed on the basis of incremental answers. For example, if SOS doctors was the 5th preferred provider, then WTP for SOS doctors = WTP for the sixth preferred provider plus the additional WTP for SOS. If SOS was the 4th preferred provider, then WTP for SOS = WTP for the sixth preferred provider plus 
the additional WTP for the 5th preferred provider + the additional WTP for SOS. Mean and median WTP values were computed for each provider in both questionnaires. Within each study sample, tests of comparison for WTP for each possible pair of providers were performed using a paired Student t-test and the Pearson chi-square test of the equality of the medians. For each provider, differences in WTP were also tested between the standard and incremental questionnaires.

We computed the ranking distribution for each type of emergency service in both the incremental and standard questionnaires. Chi-squared statistics tested for differences in the distribution of respondents' answers to the ranking question between both questionnaire types.

In order to examine the ability of the incremental approach to discriminate between various policy options, we estimated a Tobit model based on WTP values, controlling for respondents' characteristics as follows:

$$
W T P_{i j}^{*}=Z_{j} a+X_{i j} b+e_{i j}
$$

$W T P_{i j}^{*}$ is the maximum WTP of respondent $i$ for provider $j$. Some WTP values may be leftcensored (zero answers) or right-censored (above 180 euros).

$X_{i j}$ is a vector of individual characteristics.

$Z_{j}$ represents a set of option dummies. "SOS doctors" was used as the reference provider. $\varepsilon_{i j}$ and $e_{i j}$ are assumed to be normally distributed.

Models were run in incremental and standard questionnaire subsamples. The estimations provided us with a ranking of providers for each questionnaire type. All statistical analyses and regressions were run excluding those individuals who provided zero answers for all six options. As is usual in contingent valuation studies, we did this to exclude protest answers (Dziegielewska and Mendelsohn, 2007).

We tested the assumptions of normality and homoscedasticity in the Tobit models as suggested by Cameron and Trivedi (2009). We used the cluster option in all regressions because each respondent assessed all six emergency providers. 


\section{Results}

\subsection{Descriptive statistics}

The study sample comprised 280 people representative of the adult French population living in urban areas with over 100000 inhabitants. Half received the incremental version, the other half the standard version. Respondents' characteristics are shown in Table 2. The average age was 50 years old. Twenty-two percent of all respondents assessed their health status as poor. One third had used at least one of the six emergency providers in the previous year. As could be expected by the randomization procedure, there were no significant differences between the two groups in terms of age, education level, marital status, number of children under 15 years old living in the household, income, subjective health status and having supplementary coverage. However, a significant difference was found in terms of gender distribution.

\subsection{Results concerning WTP values and explicit ranking of providers}

Thirty-four respondents declared zero WTP for all six options $(12.14 \%$ in both the incremental and standard questionnaires). The results presented below exclude these people.

Mean and median WTP values for each provider in both questionnaires are shown in Table 3. Outpatient emergency centres had the lowest mean WTP in both (47.8 (incremental) and 29.8 euros (standard)) and paired Student t-tests suggested that this provider was significantly less preferred than all the others (Table 4). In both questionnaires SAMU/SMUR had the highest mean WTP, 117.6 and 47 euros, respectively. However the difference between SAMU/SMUR and ambulance/firemen was not significant in the incremental questionnaire. The same was true for the differences between SAMU/SMUR and SOS doctors and between SAMU/SMUR and doctors on duty in the standard questionnaire. Furthermore, no significant difference was observed between ambulance/firemen, SOS doctors, doctors on duty and hospital emergency units in the standard questionnaire. Instead, in the incremental questionnaire, ambulance/firemen 
was significantly preferred to SOS doctors, doctors on duty, and hospital emergency units. No significant differences were observed between these three latter providers.

Mean WTP values for all six care providers were significantly higher in the incremental questionnaires. Table 3 shows that the lowest WTP in the incremental group was higher than that in the standard group, which may suggest a kind of bias in one or other of the groups. To investigate this further, for each of the six providers, we examined the number of times it was ranked 5th or 6th, and compared WTP values across incremental and standard groups in those situations ${ }^{2}$. We repeated this analysis for situations in which each provider was ranked $1^{\text {st }}$ to $4^{\text {th }}$. Looking at the results of this analysis in Table 5, for the least preferred providers (ranked 5-6), the mean WTP is not significantly different between the incremental and standard versions (except for hospital emergency units), while the mean WTP is substantially higher in the incremental questionnaire for providers ranked $1^{\text {st }}$ to $4^{\text {th }}$. This result provides further evidence of the possibility that respondents found it more difficult to discriminate between various providers in the standard questionnaire.

Table 6 shows the distribution of provider ranking based on the explicit ranking question. Overall, the most frequently first ranked provider was SMUR/SAMU (34.6\% of respondents) followed by ambulance/firemen (29.7\%). The least preferred provider was emergency outpatient centres. Both questionnaires reflected the same pattern. However, the third and fourth most frequently first-ranked options differed between questionnaires (Table 6). Performing a chisquare test of differences in the distribution of respondents' answers to the ranking question revealed no significant differences between both questionnaire types.

\subsection{Assessing the ability of the incremental approach to provide discriminating values}

Table 7 presents the results based on equations (1) for the standard and incremental subsamples. The results suggest that the incremental approach makes it possible to discriminate between the various options while the standard approach does not. In the incremental questionnaire,

\footnotetext{
${ }^{2}$ We bundled ranks 5 and 6 in order to have enough answers in this least preferred category. We also looked at rank $6^{\text {th }}$ versus ranks 1-5 and the results are not qualitatively different from those displayed in Table 5.
} 
SAMU/SMUR and ambulance/firemen are significantly preferred to SOS doctors while in turn the latter is significantly preferred to doctors on duty and outpatient emergency centres. The evaluation is not significantly different between SOS doctors and hospital emergency units. The standard approach does not highlight any significant difference between SOS doctors and other providers except for outpatient emergency centres. This proves the inability of the standard approach to differentiate between the five most preferred providers. Furthermore, the incremental approach is fully consistent with the explicit ranking of options while the standard approach is only partially consistent (as investigated in Lamiraud et al., 2016).

Some other results also confirm that the incremental approach performs well. For example, individuals in the incremental group (but not in the standard one) with higher income were significantly more likely to declare higher WTP. Furthermore, those with "poor” or "excellent” health were more likely to declare higher WTP than those with "good" health. One possible reason for this is that those with poor health were probably more likely to need emergency care, while having excellent health may have captured an income effect and/or an education/information effect, given that those with excellent health had a significantly higher income level $(p<0.01)$ and were significantly more likely to have a university educational level $(p=0.01)$. Moreover, respondents with supplementary coverage were significantly more likely to declare higher WTP for emergency services in the incremental approach. This is in line with the phenomenon of moral hazard in the French context (Buchmueller et al., 2004) and again supports the validity of the incremental approach. Finally, our results show that those who had used emergency care during the previous year declared lower WTP values in the incremental questionnaire. This may be linked to dissatisfaction with the care provided. All questionnaires investigated whether those who used emergency services during the previous year were very satisfied/satisfied/ not satisfied with the care provided to them. Only satisfied/not satisfied users declared lower WTP than those who had not used any emergency service providers. This was true for both questionnaires but only significant in the incremental one.

The results of the tests reported in Table 7 (Tobit models) suggest that the hypotheses of normality and homoscedasticity cannot be rejected in either questionnaire. 


\section{Discussion and conclusion}

In this paper, we assessed the ability of the incremental WTP approach to provide discriminating values. In essence, our approach builds on theories of reference-dependency, asking individuals to explicitly rank alternatives and then, using the respondent's least preferred alternative as a reference point, asking for money-metric valuations of more preferred options. We compared the incremental and standard WTP approaches, using health care service providers as the good under examination. Our empirical findings are in line with our theoretical framework which shows that, in the standard approach, WTP values for each provider (which predominantly reflect improvements over the status quo), fails to discriminate between alternative providers. The incremental approach, which defines the reference point from which WTP responses are elicited, provides a more discriminating value for the $\beta$ index.

Bolstering our results, we performed various robustness checks. First, Table 8 shows the characteristics of individuals excluded from statistical and econometric analyses (i.e. with zero WTP for all of the six options). No significant differences were found between these individuals and other respondents' characteristics in terms of age, gender, education, marital status, family structure, health status, and use of emergency services in the previous year. However, those excluded had significantly higher incomes. Furthermore, they were significantly more likely to be covered by supplementary health insurance. Given that people with higher incomes may decide to self-insure and that those with supplementary coverage are expected to express higher WTP values (moral hazard), these results suggest that excluded individuals were most probably not expressing valid preferences, perhaps because they may have expressed protest answers or may have misunderstood the exercise.

Second, we checked for possible bias by the highest income group by computing mean WTP values for each provider in three income groups (Table 9). In the incremental questionnaire, the highest WTP values were found for the intermediate income group, suggesting that the highest income groups were not necessarily of key importance in shaping the results. Note that the pattern of explicit ordering of options did not differ across the income groups (Table 10). 
Finally, we tested for sensitivity of our results to the identification choice of the WTP value. Based on the preference elicitation procedure described above, we identified the maximum WTP value using the following system: going up (and down, respectively) the scale, we took the maximum WTP to be the last (first) value which respondents replied "yes" to. In order to check for robustness, we took into account the possibility that, going up the scale, the maximum WTP was an unobserved number somewhere between the last value which respondents said "yes" to and the subsequent value which they said "no" to. Accordingly, we estimated an interval data regression model in the incremental and standard questionnaires as an alternative specification to the Tobit model based on equation (2). The results were not qualitatively different from those shown in Table 7.

Our study has limitations. First, there is no equal ranking in the explicit ranking question. Indeed, one could argue that we prevented the respondents from classifying both options on equal terms. We must remember however, that individuals make such strong choices in the real world when they must prioritize between expenditures. It is of course true that some people may have no preference between two options and the WTP questions allowed for this. However, we found that for any given provider, only approximately $20 \%$ of answers indicated equal ranking with another provider, which suggests that most people indeed make strong rankings. This is also confirmed by the fact that the ranking of options provided by the explicit and implicit ranking questions is the same in the incremental questionnaire.

Second, as previously mentioned, mean WTP values were higher in the incremental questionnaires. This is in line with our theoretical framework and with previous studies using the incremental approach (Shackley and Donaldson, 2002). If there were a baseline value for the least-preferred option, we would then expect that a more-discriminating $\beta$ index would lead to higher values for remaining options. This does, however, raise the question of which WTP values to use in a cost-benefit analysis, i.e. whether to use WTP values based on the incremental or standard approach. Based on the theory and results outlined here, we would lean towards the incremental approach. As well as the theory predicting a more-discriminating $\beta$ index, the empirical results would appear to suggest that the incremental approach is more capable of 
pinpointing a structured set of preferences. Nevertheless, both approaches should be followed in future work to gather more data on the extent to which predicted differences matter.

Third, we are not clear about the extent of choice scenarios to which the incremental approach can be applied. It could be argued that, we applied it here to decide between close substitutes. However, there is no reason why it could not be applied to choices between more-disparate policy options, as Shackley and Donaldson (2002) attempted to do. The key consideration is whether there are alternative uses of resources when considering any given option.

Finally, it is true that our use of the explicit ranking to compute incremental values is based on the assumption that WTP rankings and explicit preference rankings should correspond. This in turn is based on the premise that the underlying structure of preferences is stable when respondents are asked to explicitly rank providers and to provide WTP values. Knowing that WTP questions involve monetary sacrifice while the explicit ranking question does not, this premise assumes that the ranking derived from WTP values is not influenced by the respondent having to pay money. It also would implicitly suggest that when respondents are asked to consider both (in our case by providing WTP values after answering an explicit ranking question), their opinion does not change. However, our context does not make it possible to investigate this. However, our context does not make it possible to investigate this.

We have displayed, both theoretically and empirically, the potential to overcome the major problem of embedding in contingent valuation studies, thus showing how incremental WTP values can be used to discern among various alternatives. Our hope is that this presents a more robust means of policy analysis and policy setting, one utilizing the intuitive strength of WTP methods but mitigating the problems of embedding. 


\section{Acknowledgments}

We would like to acknowledge our colleagues who attended the Joint Meeting of UK and French Health Economists, Aix en Provence, 11-13 ${ }^{\text {th }}$ January 2012, and, in particular, Stephen Birch of McMaster University. Although the term ‘marginal approach to contingent valuation' was coined in earlier work by Donaldson and colleagues in the context of encouraging patients involved in preference elicitation exercises to focus on differences between close substitutes ( i.e. different ways of treating the same problem), Birch pointed out that the use of this term is problematic, in that it does not reflect the strict interpretation of the term 'marginal' in economic theory. Accordingly, we use the term 'incremental' to emphasise the continued focus of this method on the more general issue of differences between options. We also acknowledge valuable comments from Alain Trannoy and Ken McKenzie and financial support from the Social Sciences and Humanities Research Council of Canada.

\section{Conflicts of interest}

There are no potential conflicts of interest

\section{Ethics}

The research was approved by ethic committee at ESSEC Business School 
Appendix 1: Wording of the WTP questions and hypothetical payment amounts suggested by the interviewer

\section{WTP question}

"What maximum monthly premium are you willing to pay to benefit from emergency care and out-of-hours services of provider $x$ for you and your household ? ?

The original question in French was : «Quelle prime mensuelle maximale seriez-vous prêt(e) à payer pour que vous et les membres de votre foyer bénéficient des soins de $<$ ACTEUR $>$ dans le cadre de la permanence des soins et de l'aide médicale d'urgence? »

Hypothetical payment amounts suggested by the interviewer

$\begin{array}{ll}5 \text { euros } & 100 \text { euros } \\ 10 \text { euros } & 110 \text { euros } \\ 20 \text { euros } & 120 \text { euros } \\ 30 \text { euros } & 130 \text { euros } \\ 40 \text { euros } & 140 \text { euros } \\ 50 \text { euros } & 150 \text { euros } \\ 60 \text { euros } & 160 \text { euros } \\ 70 \text { euros } & 170 \text { euros } \\ 80 \text { euros } & 180 \text { euros } \\ 90 \text { euros } & \text { More than } 180 \text { euros }\end{array}$




\section{References}

Allen, E., Dechow, P., Pope, D.G., Wu, G. (2014). Reference Dependent Preferences: Evidence from Marathon Runners. NBER Working Paper 20343.

Andreoni, J. (1990). Impure Altruism and Donations to Public Goods: A Theory of Warm-Glow Giving? Economic Journal, 100(401), 464-77.

Boardman, A.E., Greenberg, D.H., Vinning, A.R., Weimer, D.L. (1996). Cost-benefit Analysis: Concepts and Practice. Prentice-Hall, New Jersey.

Buchmueller, T.C., Couffinhal, A., Grignon, M., Perronnin, M. (2004). Access to physician services: does supplemental insurance matter? Evidence from France. Health Economics, 13, 669-687.

Cameron, A.C., Trivedi, P.K. (2009). Microeconometrics Using Stata. Stata Press.

Carson, R.T., Flores, N.E., Meade, N.F. (2000). Contingent valuation: controversies and evidence. Environmental and Resource Economics, 19, 173-210.

Dziegielewska, D.A., Mendelsohn, R. (2007). Does “No” mean "No”? A protest methodology. Environmental and resource Economics, 38 (1), 71-87

Diamond, P.A., Hausman, J.A. (1994). Contingent valuation: is some number better than no number? Journal of Economic Perspectives, 8(4), 45-64.

Giraud, R. (2010). On the Interpretation of the WTP/WTA Gap as Imprecise Utility: An Axiomatic Analysis. Economic Bulletin 30(1): 692-701.

Hackl, F., Pruckner, G.J. (2006). Demand and supply of emergency help: An economic analysis of Red Cross services. Health Policy, 77, 326-338.

Hausman, J.A. (2012). Contingent valuation: from dubious to hopeless. Journal of Economic Perspectives, 26(4), 43-56.

Heath, C., Larrick, R., Wu , G. (1999). Goals as Reference Points. Cognitive Psychology, 38(1), 79-109.

Kahneman, D., Knetsch, J.L., Thaler, R.H. (1991). Anomalies: The Endowment Effect, Loss Aversion, and Status Quo Bias. Journal of Economic Perspectives, 5(1),193-206.

Kahneman, D., Knetsch, J.L. (1992). Valuing public goods: The purchase of moral satisfaction. Journal of Environmental Economics and Management, 22(1), 57-70.

Koszegi, B., Rabin, M. (2006). A model of reference-dependent preferences. Quarterly 
Journal of Economics, 121(4), 1133-1165.

Lamiraud, K., Oxoby, R., Donaldson, C. (2016). Incremental Willingness to Pay: a Theoretical and Empirical Exposition. Theory and Decision, 80, 101-123.

Luchini, S., Protière, C., Moatti, J.P. (2003). Eliciting several willingness to pay in a single contingent valuation survey: application to health care. Health Economics, 12, 51-64.

Masatlioglu, Y., Ok, E.A.(2005). Rational Choice With Statu Quo Bias. Journal of Economic Theory 121 (1), 1-29.

Mitchell, R.C. and Carson, R.T. (1989). Using Surveys to Value Public Goods: the Contingent Valuation Method. Resources for the Future, Washington DC.

Morrison, G. (2000). The endowment effect and expected utility. Scottish Journal of Political Economy, 47 (2), 183-197.

Morrison, W.G., Oxoby R.J. (2013). The endowment effect and intertemporal choice: a laboratory investigation. Canadian Journal of Economics 46(2), 689-704.

Munro, A., Sugden, R. (2003). On the theory of reference-dependent preferences. Journal of Economic Behavior \& Organization, 50, 407-428.

Ok, E.A., Ortoleva, P., Riella, G. (2015). Revealed (P)Reference Theory. American Economic Review, 105(1), 299-321.

Olsen, J.A., Donaldson, C. (1998). Helicopters, hearts and hips: using willingness to pay to set priorities for public sector health care programmes. Social Sciences and Medicine, 46, 1-12.

Olsen, J.A., Kidholm, K., Donaldson, C., Shackley, P. (2004). Willingness to pay for public health care: a comparison of two approaches. Health Policy, 70, 217-228.

Payne, J.W., Schkade, D.A., Desvousges, W.H., Aultman, C. (2000). Valuation of Multiple Environmental Programs. Journal of Risk and Uncertainty, 21(1), 95-115.

Sagi, J.S. (2006). Anchored Preference Relations. Journal of Economic Theory 130 (1), 283-295.

Schkade, D., Payne, J. (1994). How people respond to contingent valuation questions: a verbal protocol analysis of willingness to pay for an environmental regulation. Journal of Environmental Economics and Management, 26, 88-109.

Schoemaker, P.J.H. (1982). The expected utility model: its variants, purposes, evidence and limitations. Journal of Economic Literature, 20, 529-563.

Shackley, P., Donaldson, C. (2002). Should we use willingness to pay to elicit community preferences for health care? New evidence from using a marginal approach. Journal of Health Economics, 25, 445-460. 
Smith, R.D. (2003). Construction of the contingent valuation market in health care: a critical assessment. Health Economics, 12, 609-628.

Van Uden, C.J.T., Winkens, R.A.G., Wesseling, G.J., et al. (2003). Use of out-of-hours services: a comparison between two Organisations. Emergency Medicine Journal, 20, 184-187. 
Table 1: Description of emergency providers in France

\section{Mobile means}

Fixed Means

\section{SAMU*/SMUR**}

- Heavy means sent from hospitals

- Involved in vital emergencies

- Medical doctors are on board

\section{SOS doctors}

- Dedicated to emergency care

- Equipped with an electrocardigram and perfusion devices

\section{Doctors on duty}

- Perform emergency care in addition to their usual duties

\section{Firemen/lmbulance}

- Not equipped with medical doctors

" Service d'Aide Médicale d"Urgence

* Services Mobiles d'Urgence et de Réanimation attachés aux hôpitaux

"waisons Médicales de Garde"

\section{Emergency outpatient centers***}

- Provide outpatient medical consultations

- Care is provided by a general doctor

\section{Emergency units at hospital}

- Provide initial treatment for a broad spectrum of illnesses and injuries, some of which may be life-threatening and require immediate attention

- Staff trained to work quickly and effectively even with minimal information 
Table 2: Descriptive statistics concerning the study population

\begin{tabular}{|c|c|c|c|c|}
\hline & $\begin{array}{r}\text { All } \\
n=280\end{array}$ & $\begin{array}{r}\text { Standard } \\
\text { questionnaire } \\
n=140\end{array}$ & $\begin{array}{r}\text { Incremental } \\
\text { questionnaire } \\
n=140\end{array}$ & $\mathrm{p}^{*}$ \\
\hline$\overline{\text { Age (mean) }}$ & 50.1 & 50.9 & 49.4 & 0.46 \\
\hline Male (\%) & 45.7 & 39.3 & 52.1 & 0.03 \\
\hline Education level & & & & 0.60 \\
\hline Secondary school or short professional track (\%) & 31.4 & 32.1 & 30.7 & \\
\hline High school diploma (Baccalaureat) & 21.4 & 24.3 & 18.6 & \\
\hline Short university studies (2 yrs) or long professional track (\%) & 15.7 & 14.3 & 17.1 & \\
\hline University degree higher than bachelor's (\%) & 31.4 & 29.2 & 33.5 & \\
\hline Individual is married or living in a couple (\%) & 57.1 & 57.9 & 56.4 & 0.81 \\
\hline Number of children under 15 living in the household (mean) & 0.4 & 0.4 & 0.4 & 0.95 \\
\hline Monthly household net Income $(1-10)^{\star *}($ mean $)$ & 5.7 & 5.8 & 5.6 & 0.64 \\
\hline Health status & & & & 0.83 \\
\hline Excellent self assessed health (\%) & 30.0 & 30.0 & 30.0 & \\
\hline Good self assessed health (\%) & 47.9 & 49.3 & 46.4 & \\
\hline Poor self-assessed health (\%) & 22.1 & 20.7 & 23.6 & \\
\hline Individual has supplementary health insurance coverage (\%) & 90.7 & 90.7 & 90.7 & 1.00 \\
\hline Used at least one of the 6 emergency services in the previous year & 33.3 & 29.3 & 37.9 & 0.13 \\
\hline
\end{tabular}

All statistics are weighted

* Test of difference between the standard and incremental versions

(student t-test for continuous variables, chi2 for categorical variables)

** (euros per month) $1 .<800$, 2. [800 - 1000[, 3. [1000 - 1200[, 4. [1200 - 1500[, 5. [1500 - 1800[, 6. [1800 - 2300[,

7. [2300 - 3000[, 8. [3000 - 3800[, 9. [3800 - 5300[, 10. $\geq 5300$ euros 
Table 3: Mean and median WTP by provider in the standard and incremental questionnaires

\begin{tabular}{|c|c|c|c|c|c|c|c|}
\hline & & $\begin{array}{l}\text { SMUR/ } \\
\text { SAMU }\end{array}$ & $\begin{array}{l}\text { SOS } \\
\text { doctors }\end{array}$ & $\begin{array}{l}\text { Doctors } \\
\text { on duty }\end{array}$ & $\begin{array}{l}\text { Ambulance/ } \\
\text { Firemen }\end{array}$ & $\begin{array}{l}\text { Hospital } \\
\text { emergency } \\
\text { units }\end{array}$ & $\begin{array}{c}\text { Outpatient } \\
\text { emergency } \\
\text { centres }\end{array}$ \\
\hline \multirow{4}{*}{$\begin{array}{l}\text { Standard version } \\
\quad(n=123)\end{array}$} & mean & 47,0 & 41,9 & 43,0 & 39,8 & 36,9 & 29,8 \\
\hline & & 46,9 & 41,1 & 42,8 & 41,3 & 38,5 & 35,2 \\
\hline & median & 30,0 & 30,0 & 30,0 & 30,0 & 30,0 & 20,0 \\
\hline & answers & 9,8 & 6,5 & 9,8 & 10,6 & 14,6 & 24,4 \\
\hline \multirow{4}{*}{$\begin{array}{l}\text { Incremental version } \\
\quad(\mathrm{n}=123)\end{array}$} & mean & 117,6 & 75,4 & 67,9 & 111,6 & 78,9 & 47,8 \\
\hline & std & 133,1 & 92,2 & 86,3 & 129,9 & 77,6 & 47,8 \\
\hline & median & 70,0 & 40,0 & 45,0 & 60,0 & 50,0 & 20,0 \\
\hline & $\begin{array}{l}\% \text { of zero } \\
\text { answers }\end{array}$ & 1,6 & 8,9 & 9,8 & 1,6 & 1,6 & 20.33 \\
\hline
\end{tabular}


Table 4: Test of comparison in WTP for each possible pair of providers

\begin{tabular}{|c|c|c|c|c|}
\hline & \multicolumn{2}{|c|}{ Mean comparison test (1) } & \multicolumn{2}{|c|}{ Median comparison test (2) } \\
\hline & $\begin{array}{r}\text { Standard } \\
\text { questionnaire } \\
(n=123)\end{array}$ & $\begin{array}{l}\text { Incremental } \\
\text { questionnaire } \\
(\mathrm{n}=123)\end{array}$ & $\begin{array}{r}\text { Standard } \\
\text { questionnaire } \\
(\mathrm{n}=123)\end{array}$ & $\begin{array}{l}\text { Incremental } \\
\text { questionnaire } \\
(\mathrm{n}=123)\end{array}$ \\
\hline SMUR/SAMU versus SOS doctors & 0,18 & $<0,01$ & 0,90 & 0,01 \\
\hline SMUR/SAMU versus doctors on duty & 0,33 & $<0,01$ & 0,80 & 0,01 \\
\hline SMUR/SAMU versus ambulance/firemen & 0,07 & 0,22 & 0,52 & 0,37 \\
\hline SMUR/SAMU versus hospital emergency units & $<0,01$ & $<0,01$ & 0,30 & 0,04 \\
\hline SMUR/SAMU versus outpatient emergency centres & $<0,01$ & $<0,01$ & 0,04 & $<0,01$ \\
\hline SOS doctors versus doctors on duty & 0,77 & 0,15 & 0,90 & 0,90 \\
\hline SOS doctors versus ambulance/firemen & 0,52 & $<0,01$ & 0,61 & 0,06 \\
\hline SOS doctors versus hospital emergency units & 0,22 & 0,52 & 0,37 & 0,44 \\
\hline SOS doctors versus outpatient emergency centres & $<0,01$ & $<0,01$ & 0,02 & 0,02 \\
\hline doctors on duty versus ambulance/firemen & 0,32 & $<0,01$ & 0,70 & 0,03 \\
\hline doctors on duty versus hospital emergency units & 0,05 & 0,06 & 0,44 & 0,30 \\
\hline doctors on duty versus outpatient emergency centres & $<0,01$ & $<0,01$ & 0,03 & 0,04 \\
\hline imbulance/firemen versus hospital emergency units & 0,41 & $<0,01$ & 0,70 & 0,25 \\
\hline imbulance/firemen versus outpatient emergency centres & $<0,01$ & $<0,01$ & 0,07 & $<0,01$ \\
\hline hospital emergency units versus outpatient emergency centres & 0,03 & $<0,01$ & 0,16 & $<0,01$ \\
\hline
\end{tabular}

(1) paired Student t-test

(2) Pearson chi-squared test of the equality of the medians 
Table 5: Mean and median WTP by provider in the standard and incremental questionnaires, depending on the explicit ranking

\begin{tabular}{|c|c|c|c|c|c|}
\hline & \multicolumn{2}{|c|}{$\begin{array}{l}\text { WTP in the } \\
\text { standard version } \\
(n=123)\end{array}$} & \multicolumn{2}{|c|}{$\begin{array}{l}\text { WTP in the } \\
\text { incremental version } \\
(n=123)\end{array}$} & \multirow[t]{2}{*}{$\mathrm{p}^{\star \star}$} \\
\hline & Mean & $\mathrm{n}$ & Mean & $\mathrm{n}$ & \\
\hline SMUR/SAMU ranked 5-6* & 39,5 & 11 & 30,0 & 9 & 0,65 \\
\hline SMUR/SAMU ranked $\leq 4 \mathrm{th}^{*}$ & 47,8 & 112 & 124,5 & 114 & \\
\hline SOS doctors ranked $5-6^{*}$ & 46,3 & 26 & 37,6 & 36 & 0,47 \\
\hline SOS doctors ranked $\leq 4 \mathrm{th}^{*}$ & 40,7 & 97 & 91,1 & 87 & \\
\hline Doctors on duty ranked $5-6^{*}$ & 40,9 & 61 & 37,5 & 53 & 0,66 \\
\hline Doctors on duty ranked $\leq 4 \mathrm{th}^{*}$ & 45,1 & 62 & 90,9 & 70 & \\
\hline Ambulance/ Firemen ranked 5-6* & 39,8 & 10 & 32,9 & 18 & 0,76 \\
\hline Ambulance/ Firemen ranked $\leq 4$ th $^{*}$ & 39,8 & 113 & 125,1 & 105 & \\
\hline Hospital emergency units ranked $5-6^{*}$ & 43,8 & 35 & 85,8 & 29 & 0,01 \\
\hline Hospital emergency units ranked $\leq 4 \mathrm{th}^{*}$ & 34,2 & 88 & 76,8 & 94 & \\
\hline Outpatient emergency centres ranked $5-6^{*}$ & 28,1 & 103 & 30,5 & 101 & 0,62 \\
\hline Outpatient emergency centres ranked $\leq 4$ th $^{*}$ & 38,8 & 20 & 127,0 & 22 & \\
\hline
\end{tabular}


Table 6: Distribution of provider ranking

\begin{tabular}{|c|c|c|c|c|c|c|c|c|}
\hline & & 1st & 2nd & 3rd & 4th & 5th & 6th & $p^{*}$ \\
\hline \multirow{6}{*}{$\begin{array}{l}\text { All questionnaires } \\
(n=246)\end{array}$} & SMUR/SAMU & 34,6 & 32,5 & 17,1 & 7,7 & 5,3 & 2,9 & \\
\hline & SOS doctors & 13,0 & 16,3 & 22,0 & 23,6 & 17,9 & 7,3 & \\
\hline & Doctors on duty & 7,3 & 6,9 & 15,9 & 23,6 & 35,0 & 11,4 & \\
\hline & Ambulance/ Firemen & 29,7 & 26,8 & 21,1 & 11,0 & 6,9 & 4,5 & \\
\hline & Hospital emergency units & 12,2 & 15,0 & 20,7 & 26,0 & 19,5 & 6,5 & \\
\hline & Outpatient emergency centres & 3,3 & 2,4 & 3,3 & 8,1 & 15,5 & 67,5 & \\
\hline \multirow{6}{*}{$\begin{array}{l}\text { Standard questionnaire } \\
(\mathrm{n}=123)\end{array}$} & SMUR/SAMU & 32,5 & 32,5 & 18,7 & 7,3 & 6,5 & 2,4 & 0,91 \\
\hline & SOS doctors & 17,1 & 16,3 & 22,8 & 22,8 & 16,3 & 4,9 & 0,34 \\
\hline & Doctors on duty & 8,1 & 8,9 & 11,4 & 22,0 & 40,7 & 8,9 & 0,12 \\
\hline & Ambulance/ Firemen & 30,9 & 27,6 & 20,3 & 13,0 & 3,3 & 4,9 & 0,30 \\
\hline & Hospital emergency units & 10,6 & 12,2 & 22,8 & 26,0 & 21,1 & 7,3 & 0,71 \\
\hline & Outpatient emergency centres & 0,8 & 2,4 & 4,1 & 8,9 & 12,2 & 71,5 & 0,19 \\
\hline \multirow{6}{*}{$\begin{array}{l}\text { Incremental questionnaire } \\
(n=123)\end{array}$} & SMUR/SAMU & 36,6 & 32,5 & 15,5 & 8,1 & 4,1 & 3,3 & \\
\hline & SOS doctors & 8,9 & 16,3 & 21,1 & 24,4 & 19,5 & 9,8 & \\
\hline & Doctors on duty & 6,5 & 4,9 & 20,3 & 25,2 & 29,3 & 13,8 & \\
\hline & Ambulance/ Firemen & 28,5 & 26,0 & 22,0 & 8,9 & 10,6 & 4,1 & \\
\hline & Hospital emergency units & 13,8 & 17,9 & 18,7 & 26,0 & 17,9 & 5,7 & \\
\hline & Outpatient emergency centres & 5,7 & 2,4 & 2,4 & 7,3 & 18,7 & 63,4 & \\
\hline
\end{tabular}


Table 7: Estimation of a Tobit model based on WTP values

Standard questionnaire Incremental questionnaire

(1)

\section{SAMU/SMUR}

\section{SOS doctors}

Doctors on duty

Ambulance/ Firemen

Hospital emergency units

Outpatient emergency centres

Male

Age $18-30$

Age $31-50$

Age $51-65$

Age $>65$

Excellent health status

Good health status

Poor health status

Income

Number of children under 15 living in the household

Individual has supplementary health insurance coverage

Used at least one emergency service in the previous year

n

Test of normality of residuals (null hypothesis: normal errors)

Test of homescedasticity

\begin{tabular}{rr}
\hline$(1)$ & $(1)$ \\
\hline 4,575 & $49,141^{* * *}$ \\
$r e f$ & $r e f$ \\
0,418 & $-9,658^{*}$ \\
$-5,193$ & $42,026^{* * *}$ \\
-9.243 & 4,094 \\
$-18.606^{* * *}$ & $-50,077^{* * *}$ \\
$-2,837$ & 30,991 \\
21,686 & $95,272^{*}$ \\
29,581 & 45,806 \\
$-2,619$ & 43,215 \\
$r e f$ & $r e f$ \\
$-3,980$ & $47.327^{* * *}$ \\
$r e f$ & $r e f$ \\
$-1,790$ & $95.457^{* * *}$ \\
3,133 & $9.856^{* * *}$ \\
$-12,541$ & $-3,853$ \\
$-9,299$ & $79.519^{* * *}$ \\
$-10,967^{*}$ & $-44.660^{* * *}$ \\
\hline 738 & 738 \\
\hline 0,74 & 0,83 \\
0,66 & 0,70 \\
\hline
\end{tabular}

* significant at 0.10 level, ${ }^{* *}$ significant at 0.05 level, ${ }^{* * *}$ significant at 0.001 level

All models include geographical areas (department) dummies

*Individuals with zero WTP answers for all six options are excluded 
Table 8: Characteristics of individuals providing zero WTP values for all 6 providers

\begin{tabular}{|c|c|c|c|}
\hline & $\begin{array}{r}\text { Individual with zero } \\
\text { WTP values for } \\
\text { all six options } \\
n=34\end{array}$ & Others & $p^{*}$ \\
\hline$\overline{\text { Age (mean) }}$ & 50,10 & 50,10 & 1 \\
\hline Male (\%) & 47,06 & 45,53 & 0,87 \\
\hline Secondary school or short professional track (\%) & 26,47 & 32,11 & 0,72 \\
\hline High school diploma (Baccalaureat) & 26,47 & 20,73 & \\
\hline Short university studies (2 yrs) or long professional track (\%) & 11,76 & 16,26 & \\
\hline University degree higher than Bachelor's degree (\%) & 35,29 & 30,89 & \\
\hline Individual is married or living in a couple (\%) & 70,59 & 55,28 & 0,09 \\
\hline Number of children under 15 living in the household (mean) & 0,21 & 0,45 & 0,14 \\
\hline Income $(1-10)$ (mean) & 7,54 & 5,51 & $<0.01$ \\
\hline Excellent self assessed health (\%) & 17,65 & 31,71 & 0,23 \\
\hline Good self assessed health (\%) & 58,82 & 46,34 & \\
\hline Poor self-assessed health (\%) & 23,53 & 21,95 & \\
\hline Individual has supplementary health insurance coverage (\%) & 100,00 & 89,43 & 0,05 \\
\hline Used at least one of the 6 emergency services in the previous year & 26,47 & 34,55 & 0,35 \\
\hline
\end{tabular}

* Test of difference between individuals with zero WTP for all six options and other individuals (student t-test for continuous variables, chi2 for categorical variables) 
Table 9: Mean WTP by income level

\begin{tabular}{|c|c|c|c|c|c|c|c|}
\hline & & $\begin{array}{l}\text { SMUR/ } \\
\text { SAMU }\end{array}$ & $\begin{array}{l}\text { SOS } \\
\text { doctors }\end{array}$ & $\begin{array}{l}\text { Doctors } \\
\text { on duty }\end{array}$ & $\begin{array}{l}\text { Ambulance/ } \\
\text { Firemen }\end{array}$ & $\begin{array}{l}\text { Hospital } \\
\text { emergency } \\
\text { units }\end{array}$ & $\begin{array}{l}\text { Outpatient } \\
\text { emergency } \\
\text { centres }\end{array}$ \\
\hline $\begin{array}{l}\text { Incremental questionnaire } \\
(\mathrm{n}=123)\end{array}$ & $\begin{array}{l}\text { net income }<1500(n=45) \\
\text { net income } 1500-3000(n=46) \\
\text { net income }>3000(n=32)\end{array}$ & $\begin{array}{r}71,8 \\
153,7 \\
130,2\end{array}$ & $\begin{array}{l}46,3 \\
91,6 \\
92,9\end{array}$ & $\begin{array}{l}42,4 \\
79,8 \\
86,8\end{array}$ & $\begin{array}{r}73,1 \\
135,5 \\
133,4\end{array}$ & $\begin{array}{l}50,8 \\
97,2 \\
93,4\end{array}$ & $\begin{array}{l}31,5 \\
54,0 \\
62,4\end{array}$ \\
\hline $\begin{array}{l}\text { Standard questionnaire } \\
(n=123)\end{array}$ & $\begin{array}{l}\text { net income }<1500(n=44) \\
\text { net income } 1500-3000(n=47) \\
\text { net income }>3000(n=32)\end{array}$ & $\begin{array}{l}40,5 \\
44,4 \\
64,4\end{array}$ & $\begin{array}{l}41,0 \\
42,6 \\
45,9\end{array}$ & $\begin{array}{l}44,8 \\
46,9 \\
37,7\end{array}$ & $\begin{array}{l}35,9 \\
42,1 \\
44,4\end{array}$ & $\begin{array}{l}36,9 \\
32,3 \\
45,3\end{array}$ & $\begin{array}{l}28,7 \\
30,4 \\
32,7\end{array}$ \\
\hline
\end{tabular}


Table 10: Pattern of explicit orderings of options across the income groups

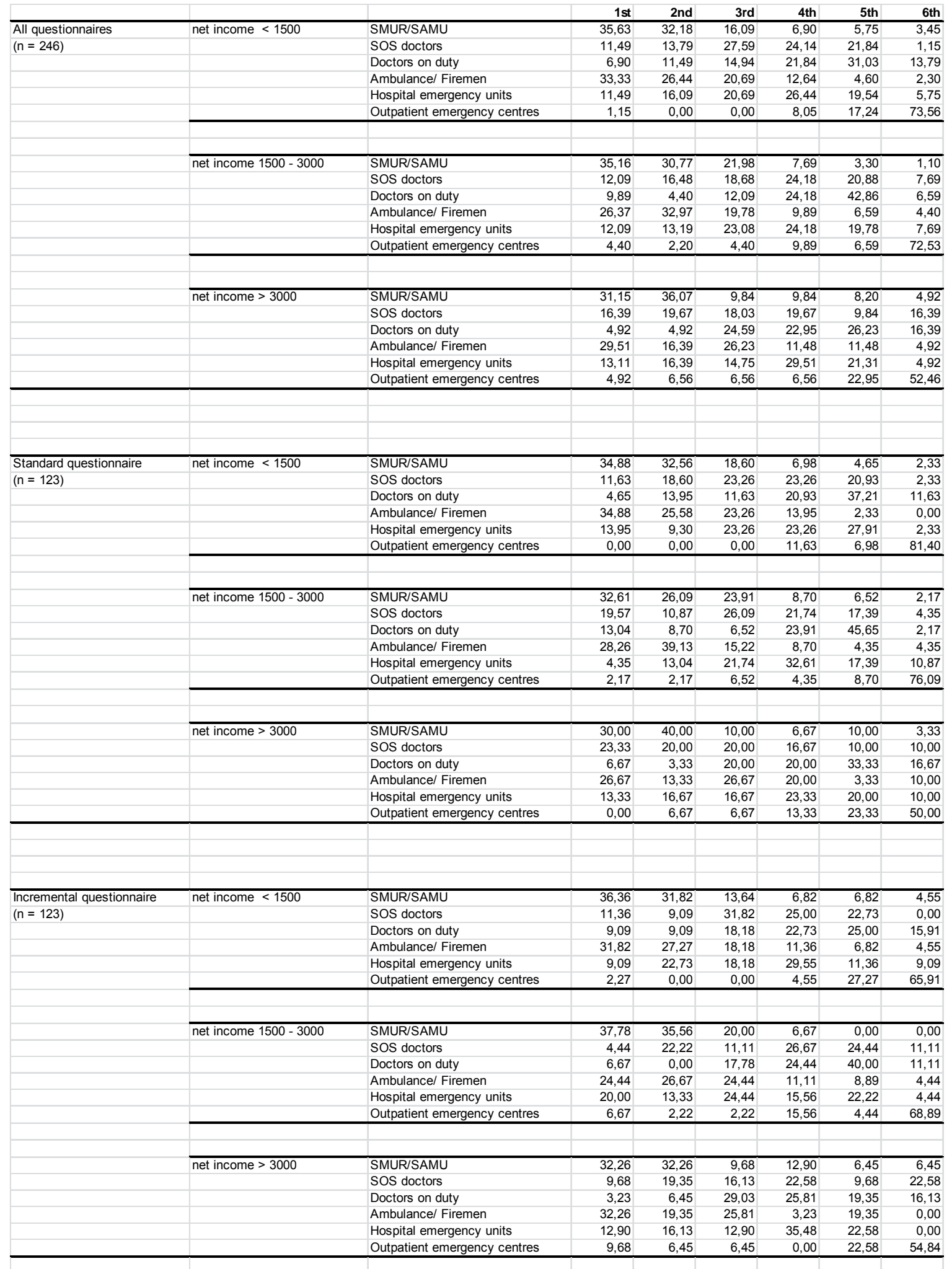


Figure 1: Reference dependent preferences in commodity space.

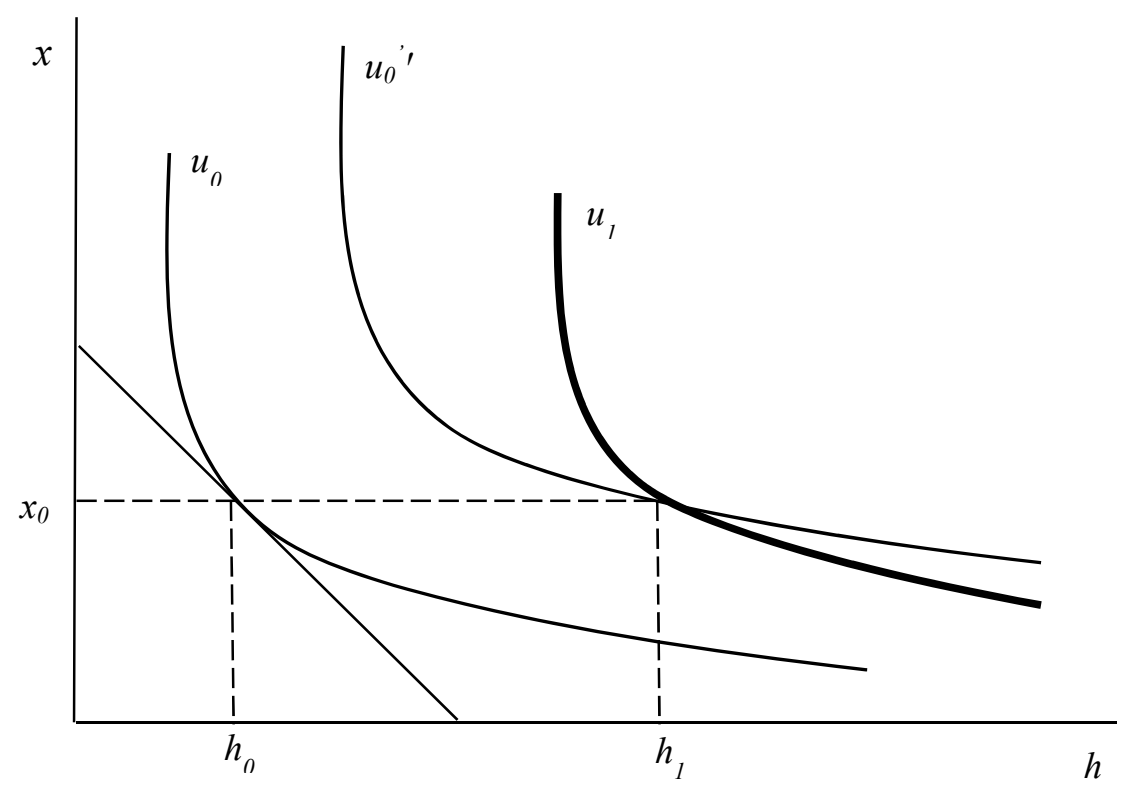


Figure 2: Standard WTP measure comparing $h_{1}$ and $h_{2}$.

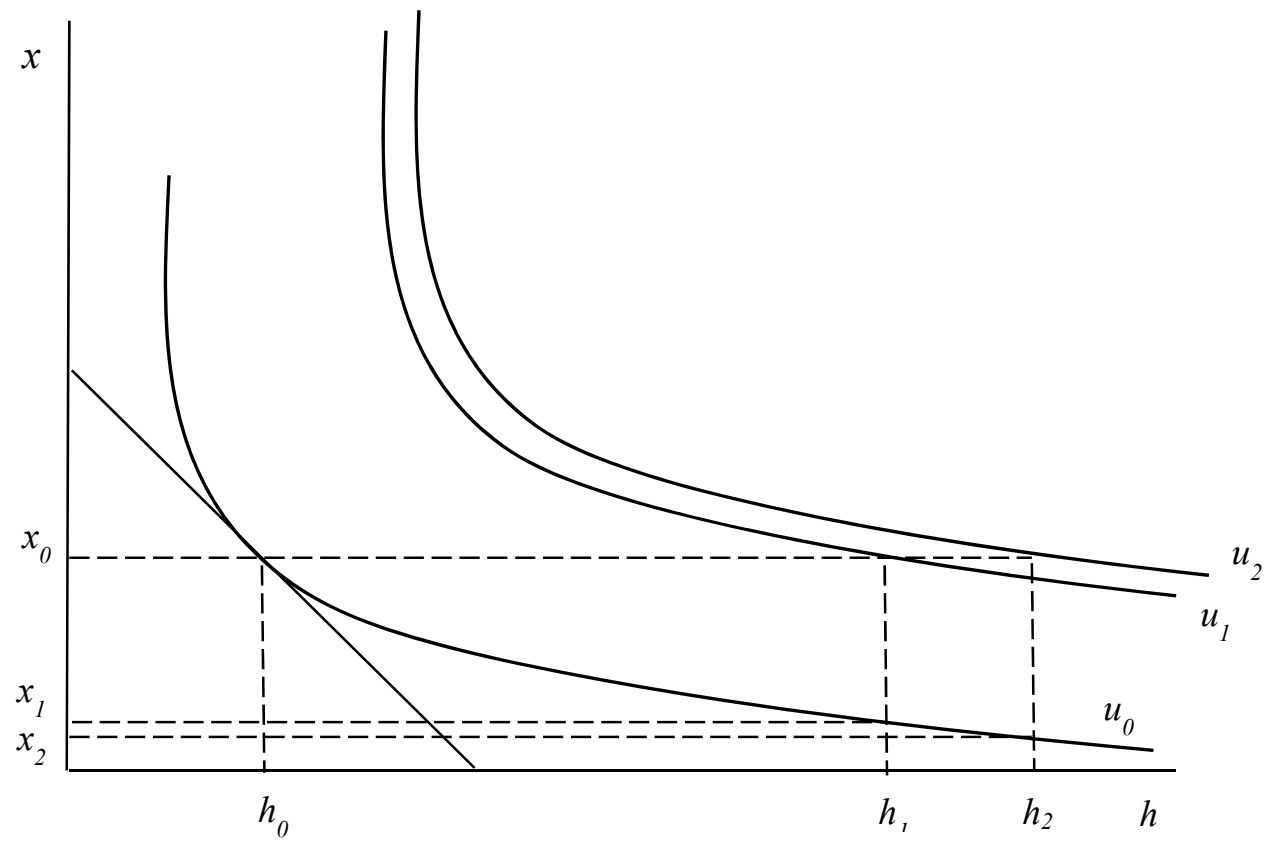


Figure 3: Incremental WTP with reference dependent preferences

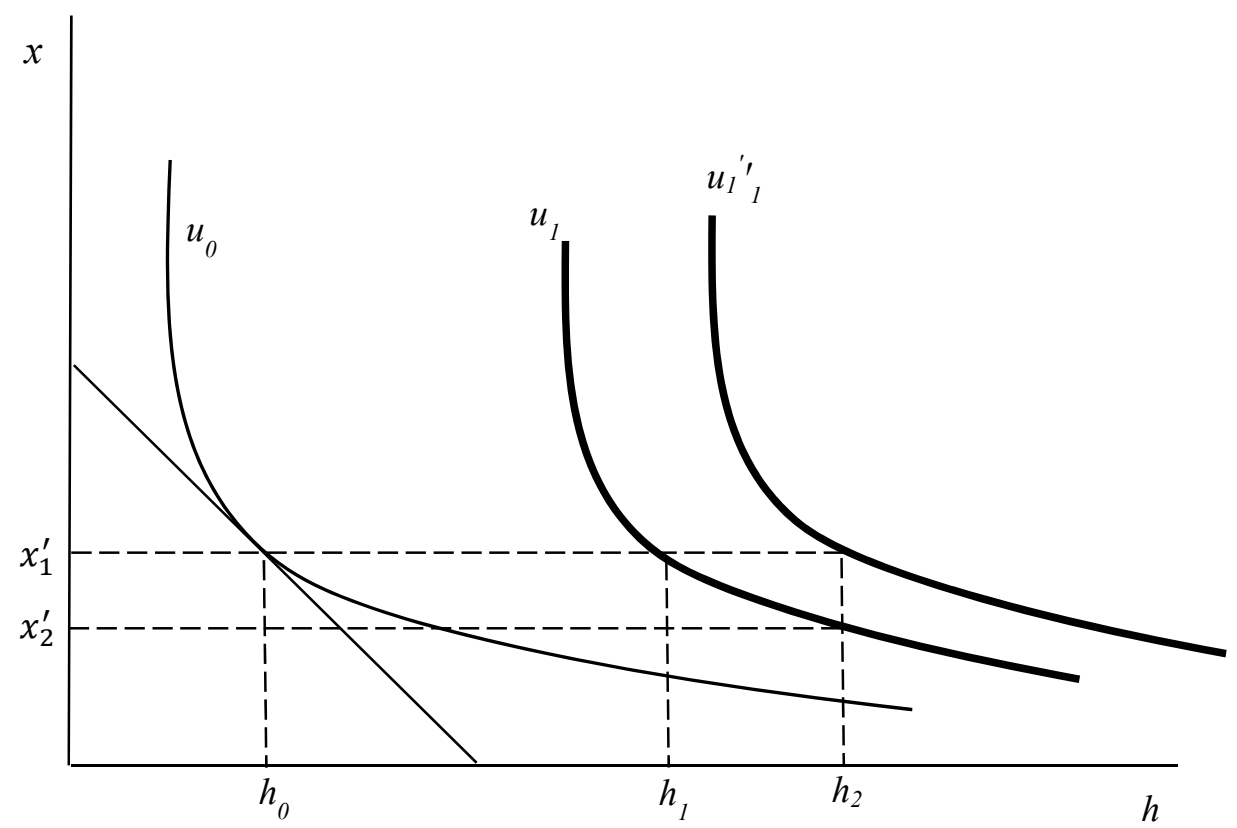


ESSEC Business School

3, avenue Bernard-Hirsch

CS 50105 Cergy

95021 Cergy-Pontoise Cedex

France

Tél. + $33(0) 134433000$

www.essec.edu
ESSEC Executive Education

CNIT BP 230

92053 Paris-La Défense

France

Tél. +33 (0) 146924900

www.executive-education.essec.fr
ESSEC Asia-Pacific

5 Nepal Park

Singapore 139408

Tél. +65 68849780

www.essec.edu/asia

\section{SINGAPOUR}

Contact :

Centre de Recherche

+33 (0)134433091

research.center@essec.fr

ISSN 1291-9616 